\title{
Efeito Alelopático de Capim-BraguiáRIa (Brachiaria decumbens) sobre o Crescimento Inicial de Sete Espécies de Plantas Cultivadas $^{1}$
}

\author{
Allelopathic Effects of Brachiaria decumbens on the Initial Development of Seven Crops
}

SOUZA, L.S. ${ }^{2}$, VELINI, E.D. ${ }^{3}$, MARTINS, D. ${ }^{3}$ e ROSOLEM, C.A. ${ }^{3}$

\begin{abstract}
RESUMO - O presente trabalho constou de sete experimentos, que foram conduzidos na Faculdade de Ciências Agronômicas, campus de Botucatu, UNESP, São Paulo, Brasil, com o objetivo de avaliar os efeitos alelopáticos de Brachiaria decumbens, colhida em diferentes épocas, sobre o crescimento inicial de milho, arroz, trigo, soja, feijão, algodão e capim-braquiária (B. decumbens), bem como a dinâmica do nitrogênio no solo. A parte aérea de $B$. decumbens foi coletada durante as estações seca (outono-inverno) e chuvosa (primavera-verão), em área de pastagem localizada no município de Botucatu-SP. A matéria seca triturada de B. decumbens foi incorporada ao solo dos vasos na proporção de 3\% p/p. O delineamento experimental foi inteiramente casualizado, com cinco repetições. Contando-se a partir do transplante, o experimento foi conduzido por 21 dias para milho e feijão, 24 dias para soja e trigo, 28 dias para arroz e 30 dias para algodão e capim-braquiária. O crescimento dessas plantas foi reduzido com a adição de capim-braquiária para as duas épocas, sendo o próprio capim-braquiária o mais afetado. Os efeitos inibitórios foram mais intensos para capim-braquiária coletado na estação chuvosa. A incorporação da matéria seca da parte aérea de $B$. decumbens reduziu, significativamente, os teores de nitrato no solo, em todos os estudos realizados.
\end{abstract}

Palavras-chave: alelopatia, culturas anuais, Brachiaria, nitrogênio.

\begin{abstract}
This work consisted of seven experiments carried out at UNESP - Botucatu-SP Brazil to evaluate the allelopathic effects of Brachiaria decumbens collected in different seasons on the initial growth of corn, rice, wheat, soybean, bean, cotton and B. decumbens and to evaluate nitrogen dynamics in the soil. The upper part of $\boldsymbol{B}$. decumbens was collected during the dry and wet seasons in a pasture area located in the district of Botucatu-SP. The dry matter was ground and incorporated into the soil in $3 \% \mathrm{w} / \mathrm{w}$. The experimental design was arranged in completely randomized plots with 5 replications. Starting from the transplanting day, the experiment was conducted for 21 days for corn and bean, 24 days for soy and wheat, 28 days for rice and 30 days for cotton and $\mathbf{B}$. decumbens. The growth of those plants was reduced with the addition of $\boldsymbol{B}$. decumbens collected during both seasons. Among the seven tested crops, B. decumbens was the most affected. The inhibitory effects were most intense for B.decumbens collected during the rainy season. B. decumbens dry matter reduced significantly the contents of nitrate in the soil in all the experiments carried out.
\end{abstract}

Keywords: allelopathy, annual cultures, Brachiaria, nitrogen.

Recebido para publicação em 13.3.2006 e na forma revisada em 10.11.2006.

Parte da tese de doutorado do primeiro autor apresentada à FCA/UNESP-Botucatu-SP.

2 Prof. Dr., Dep. de Fitotecnia, Faculdade de Ciências Agrárias, Universidade de Marília - FCA/UNIMAR. Av. Higyno Muzzi Filho, 1001, 17525-902 Marília-SP <lsouza-ca@unimar.br>. ${ }^{3}$ Prof. Dr., Dep. de Produção Vegetal-Agricultura, Faculdade de Ciências Agronômicas - FCA/UNESP-Botucatu, Caixa Postal 237, 18603-970 Botucatu-SP. 


\section{INTRODUÇÃO}

A alelopatia é definida como o efeito inibitório ou benéfico, direto ou indireto, de uma planta sobre outra, via produção de compostos químicos que são liberados no ambiente.

Esse fenômeno ocorre em comunidades naturais de plantas (Gressel \& Holm, 1964) e pode, também, interferir no crescimento das culturas agrícolas (Bell \& Koeppe, 1972; Muller, 1966). Provavelmente, a conseqüência mais significativa da alelopatia seja a alteração da densidade populacional e do desenvolvimento das plantas. A alelopatia assume grande importância quando resíduos de vegetais são deixados sobre a superfície ou incorporados anualmente ao solo (Guenzi et al., 1967; Tukey Jr., 1969). Isso indica que a interferência alelopática é tão importante no plantio convencional quanto no plantio direto e nas pastagens.

Além disso, algumas plantas daninhas, situadas em agroecossistemas, podem apresentar efeito alelopático sobre culturas agrícolas. Por exemplo, Abutilon theophrasti é responsável pelo efeito alelopático em milho e soja, descritos por Bhowmik \& Doll (1979, 1982). Sabe-se, também, que a redução de nitrogênio, em leguminosas e gramíneas, é particularmente sensivel à inibição pela alelopatia. Isso foi demonstrado pelo efeito de Agropyron repens sobre a cultura do milho (Buchholtz, 1971).

Cochran et al. (1977) demonstraram que o desenvolvimento reduzido e a baixa produtividade de culturas são atribuídos a compostos lixiviados no solo, os quais são resultantes da decomposição de resíduos vegetais por via microbiana. Atualmente, no Brasil, utiliza-se a semeadura ou a manutenção de Brachiaria decumbens como uma prática conservacionista. Por exemplo, em áreas com antigas pastagens com $B$. decumbens é comum a instalação de maciços florestais com Eucaliptus e Pinus, onde pode ocorrer efeito inibitório por B. decumbens (Souza et al., 2003). Em relação às culturas anuais, no Cerrado, existem aproximadamente 2,2 milhões de hectares com plantio direto (Scaléa, 1997), além de enormes áreas de pastagens perenes de $B$. decumbens. Estas pastagens são reformadas ou substituídas por culturas anuais, como milho e soja, pelo sistema de plantio direto ou pelo preparo convencional, incorporando-se a palhada ao solo.

Segundo Rice (1984), as diversas fases do ciclo do nitrogênio são afetadas pela alelopatia, modificando as relações entre o nitrogênio livre, a fixação de nitrogênio e a adição de matéria orgânica Existem pesquisas que relatam a interferência da alelopatia na dinâmica do nitrogênio no solo (Stiven, 1952; Mills, 1953; Meiklejohn, 1962). Souza et al. (1997), com objetivo de determinar o potencial alelopático de $B$. decumbens sobre o crescimento inicial de limão-cravo (Citrus limonia), verificaram que a incorporação de $B$. decumbens no solo reduziu drasticamente a quantidade de nitrogênio na solução do solo.

Desse modo, este trabalho teve como objetivos determinar os efeitos alelopáticos de $B$. decumbens sobre o crescimento inicial de várias espécies de plantas anuais, como milho (Zea mays), soja (Glycine max), feijão (Phaseolus vulgaris), arroz (Oryza sativa), trigo (Triticum aestivum), algodão (Gossypium hirsutum) e capim-braquiária (B. decumbens), e avaliar a dinâmica do nitrogênio no solo.

\section{MATERIAL E MÉTODOS}

O presente trabalho constou de sete experimentos, que foram conduzidos em casa de vegetação, no Departamento de Agricultura e Melhoramento Vegetal da Faculdade de Ciências Agronômicas - campus de Botucatu - UNESP, localizada na Fazenda Experimental Lageado, no município de Botucatu, São Paulo, Brasil.

O substrato utilizado nos experimentos constituiu-se de terra coletada da camada arável de um Latossolo Roxo, ocorrente na Fazenda Lageado. A terra, depois de coletada, foi seca à sombra e passada em peneira com malhas de $5 \mathrm{~mm}$, sendo enviada para análise química de nutrientes, pelo método de Raij \& Quaggio (1983). As principais características químicas são apresentadas na Tabela 1 .

A partir dos resultados da análise de solo (Tabela 1), foram aplicadas as quantidades de fertilizantes necessárias para elevar os teores de nutrientes para os seguintes valores: $\mathrm{N}=100 \mathrm{mg} \mathrm{dm}^{-3}$ (uréia), $\mathrm{P}=200 \mathrm{mg} \mathrm{dm}^{-3}$ (superfosfato simples) e $\mathrm{K}=150 \mathrm{mg} \mathrm{dm}^{-3}$ (cloreto de potássio). 
Foram utilizados vasos plásticos com capacidade para 7 litros, contendo $5 \mathrm{~kg}$ do substrato. Para evitar eventuais perdas de água por percolação durante o processo de irrigação, foram uzados vasos com base sem drenos. As plantas de B. decumbens foram coletadas durante as estações seca e chuvosa, em área de pastagem localizada no município de Botucatu-SP. A parte aérea das plantas (folhas, colmos e bainhas coletadas antes do florescimento) foi seca em estufa de circulação forçada de ar a $60{ }^{\circ} \mathrm{C}$ por 72 horas, sendo, a seguir, triturada em moinho (malha de $0,3 \mathrm{~mm}$ ) e armazenada em câmara seca. Uma pequena porção desse material foi utilizada para determinação dos teores de macro e micronutrientes e de carbono, empregando o método da resina (Raij \& Quaggio, 1983). Os teores foliares de carbono de $B$. decumbens foram obtidos pelo método descrito por Tedesco et al. (1985). Os teores de nutrientes e carbono da matéria seca em $B$. decumbens estão apresentados na Tabela 2.

A matéria seca de $B$. decumbens foi adicionada e homogeneizada no substrato numa proporção de $3 \%(\mathrm{p} / \mathrm{p})$, constituindo três tratamentos com duas épocas sazonais de coleta, época seca e das águas, e uma testemunha (ausência de matéria seca de $B$. decumbens) para cada experimento. O delineamento experimental foi inteiramente casualizado, com cinco repetições. Os experimentos constaram do plantio de sete espécies vegetais, sendo, entre estas, a própria $B$. decumbens; três espécies agrícolas monocotiledôneas: híbrido de milho 769-Dina-precoce, arroz cultivar IAC-201 e trigo cultivar IAC-24; e três espécies agrícolas dicotiledôneas: soja cultivar IAC-8, feijão cultivar IAC-carioca e algodão cultivar IAC-20. As sementes foram pré-germinadas em câmara de germinação, antes de serem transplantadas nos vasos.

A instalação dos experimentos foi feita pelo transplante de quatro plântulas das espécies indicadoras estudadas por vaso. Posteriormente, foi feito um desbaste, eliminando-se $50 \%$ das plantas. Ao longo do experimento, a irrigação foi efetuada de forma a restabelecer o nível de $70 \%$ da máxima capacidade de retenção do substrato, controlando-se a necessidade de irrigação por pesagem dos vasos, feita a cada dois dias. A temperatura da casa de vegetação esteve entre 25 e $35^{\circ} \mathrm{C}$ no período diurno e entre 16 e $20{ }^{\circ} \mathrm{C}$ no período noturno. Procedeu-se à mudança na posição dos vasos a cada dois dias.

Contando-se a partir do transplante, o experimento foi conduzido por 21 dias para milho e feijão, 24 dias para soja e trigo, 28 dias para arroz e 30 dias para algodão e capimbraquiária.

Ao final de cada experimento, foram determinados os teores de nitrato $\left(\mathrm{NO}_{3}\right)$, amônia

Tabela 1 - Resultados da análise química da terra utilizada como substrato

\begin{tabular}{|c|c|c|c|c|c|c|c|c|c|}
\hline \multirow{2}{*}{$\begin{array}{l}\text { M.O. } \\
\left(\mathrm{g} \mathrm{kg}^{-1}\right)\end{array}$} & \multirow{2}{*}{$\begin{array}{c}\mathrm{pH} \\
\left(\mathrm{CaCl}_{2}\right) \\
\end{array}$} & \multirow{2}{*}{$\begin{array}{c}\mathrm{P} \\
\left(\mathrm{mg} \mathrm{dm}^{-3}\right) \\
\end{array}$} & $\mathrm{K}^{+}$ & $\mathrm{Ca}^{++}$ & $\mathrm{Mg}^{++}$ & $\left(\mathrm{H}^{++} \mathrm{Al}^{+3}\right)$ & $S$ & \multirow{2}{*}{ CTC } & \multirow{2}{*}{$\mathrm{V}(\%)$} \\
\hline & & & \multicolumn{5}{|c|}{$\left(\mathrm{cmol}_{\mathrm{c}} \mathrm{dm}^{-3}\right)$} & & \\
\hline 28,0 & 4,8 & $11^{1 /}$ & 0,24 & 3,1 & 1,1 & 3,8 & 4,4 & 8,2 & 53,6 \\
\hline
\end{tabular}

${ }^{1 /}$ método da resina (Raij \& Quaggio, 1983).

Tabela 2 - Teores médios de macro e micronutrientes e de carbono na matéria seca de $B$. decumbens coletada na época da seca e das águas

\begin{tabular}{|c|c|c|c|c|c|c|c|c|c|c|c|}
\hline \multirow{2}{*}{ Matéria seca-Época } & $\mathrm{N}$ & $\mathrm{P}$ & $\mathrm{K}$ & $\mathrm{Ca}$ & $\mathrm{Mg}$ & $\mathrm{C}$ & $\mathrm{Cu}$ & $\mathrm{Zn}$ & $\mathrm{Fe}$ & $\mathrm{Mn}$ & \multirow{2}{*}{$\mathrm{C} / \mathrm{N}$} \\
\hline & \multicolumn{6}{|c|}{$\left(\mathrm{g} \mathrm{kg}^{-1}\right)$} & \multicolumn{4}{|c|}{$\left(\mathrm{mg} \mathrm{kg}^{-1}\right)$} & \\
\hline B. decumbens-secas & 9,05 & 0,82 & 7,60 & 6,53 & 3,23 & 354,0 & 250 & 606 & 1.611 & 190 & $39: 1$ \\
\hline B. decumbens-águas & 9,40 & 0,75 & 7,90 & 6,08 & 2,55 & 420,0 & 200 & 405 & 1.525 & 173 & $44: 1$ \\
\hline
\end{tabular}


$\left(\mathrm{NH}_{3}\right)$ e nitrogênio inorgânico, orgânico e total do solo. Utilizou-se a metodologia de Keeney \& Nelson (1982). Concomitantemente, procedeu-se ao corte da parte aérea das plantas, separando-se as folhas do caule e medindo-se em seguida a área foliar, utilizando medidor automático da marca Hayashi Denkoh, modelo AAM-7. Os teores de clorofila foram avaliados em todas as folhas das culturas com o uso de equipamento Minolta SPAD 502. Em seguida, o substrato foi lavado com água, para retirada das raizes. As folhas, os caules e as raízes foram secos, separadamente, em estufa de circulação forçada de ar a $65{ }^{\circ} \mathrm{C}$, por 72 horas.

Para obtenção dos teores foliares de nitrogênio, foi utilizada a metodologia do semimicro Kjeldahl, ou seja, digestão por ácido sulfúrico seguida por destilação e titulação.

Os resultados foram submetidos à análise de variância para o teste F. Procedeu-se à comparação dos tratamentos por contrastes de médias. Em vez de comparar os valores de $\mathrm{F}$ obtidos com os valores tabelados em níveis de 1, 5 e 10\% de probabilidade, optou-se pelo nível de significância, que corresponde à probabilidade de erro quando se admite que as duas médias comparadas são diferentes. Nas comparações entre tratamentos considerados de menor importância para o entendimento dos resultados, optou-se pela utilização do teste $\mathrm{t}$ em nível de 10\% de probabilidade, uma vez que foi impossivel apresentar os niveis de significância de todos os possiveis contrastes entre médias de tratamentos.

\section{RESULTADOS E DISCUSSÃO}

Nas Tabelas 3 a 9 são apresentados os resultados referentes aos teores totais de nitrogênio e suas frações, nos experimentos envolvendo as sete espécies de plantas utilizadas como indicadoras. De modo geral, os teores de nitrogênio orgânico e total foram superiores nos tratamentos com incorporação de $B$. decumbens ao solo. Em contraste, os teores de $\mathrm{N}$ na forma mineral sempre foram inferiores, em maior ou menor intensidade, nestes tratamentos.

Em termos médios, os teores totais de nitrogênio foram elevados em $475 \mathrm{mg} \mathrm{dm}^{-3}$ nos tratamentos com incorporação de B. decumbens. Como os teores de $\mathrm{N}$ na matéria seca da gramínea obtida nas estações seca e chuvosa foram de 9,05 e 9,40 $\mathrm{g} \mathrm{kg}^{-1}$ (Tabela 2), respectivamente, seriam esperadas elevações dos teores totais de $\mathrm{N}$ no solo de 263 e $274 \mathrm{mg} \mathrm{dm}^{-3}$, também de modo respectivo. Há diferença de aproximadamente $200 \mathrm{mg} \mathrm{dm}^{-3}$ entre os valores esperados e os valores médios encontrados. Como se verá adiante, as quantidades extraídas pelas culturas foram muito pequenas quando comparadas às encontradas no solo. Portanto, as diferenças nas quantidades extraídas pelas culturas, inferiores nos tratamentos com matéria seca de B. decumbens, são insuficientes para justificar os menores teores totais de $\mathrm{N}$ no solo das testemunhas.

Ainda quanto ao teor de $\mathrm{N}$ na forma mineral (amônia + nitrato), somente no ensaio

Tabela 3 - Níveis de significância e valores médios dos teores de nitrogênio total e de suas formas no solo onde se cultivou o milho, após incorporação de $B$. decumbens

\begin{tabular}{|c|c|c|c|c|c|}
\hline \multirow{2}{*}{ Tratamento } & $\mathrm{N}-\mathrm{NH}_{3}$ & $\mathrm{~N}-\mathrm{NO}_{3}$ & N-Mineral & N-Orgânico & N-Total \\
\hline & \multicolumn{5}{|c|}{$(\mathrm{ppm})$} \\
\hline Testemunha & 59,15 & 63,35 & 122,50 & $1.361,50$ & $1.484,00$ \\
\hline B. decumbens - seca & 59,50 & 15,40 & 74,90 & $1.691,20$ & $1.766,10$ \\
\hline B. decumbens - águas & 57,40 & 11,55 & 68,95 & $1.659,35$ & $1.728,30$ \\
\hline Níveis de significância de F: & $\alpha^{*}$ & $\alpha$ & $\alpha$ & $\alpha$ & $\alpha$ \\
\hline Tratamentos & 73,36 & 0,08 & 11,97 & 0,68 & 2,14 \\
\hline Testemunha vs seca & 97,77 & 0,01 & 2,43 & 0,05 & 0,18 \\
\hline Testemunha vs águas & 88,87 & 0,01 & 1,43 & 0,10 & 0,42 \\
\hline Seca vs águas & 86,66 & 56,71 & 73,81 & 60,20 & 55,76 \\
\hline $\mathrm{CV}(\%)$ & 32,63 & 33,88 & 30,61 & 5,91 & 5,89 \\
\hline
\end{tabular}

* Porcentagem. 
envolvendo as culturas do trigo e feijão os valores foram próximos nos três tratamentos. Para todas as demais culturas, os valores médios dessa característica foram muito inferiores nos tratamentos com matéria seca de $B$. decumbens.

Tabela 4 - Níveis de significância e valores médios dos teores de nitrogênio total e de suas formas no solo onde se cultivou o arroz, após incorporação de $B$. decumbens

\begin{tabular}{|c|c|c|c|c|c|}
\hline \multirow{2}{*}{ Tratamento } & $\mathrm{N}-\mathrm{NH}_{3}$ & $\mathrm{~N}-\mathrm{NO}_{3}$ & N-Mineral & N-Orgânico & N-Total \\
\hline & \multicolumn{5}{|c|}{$(\mathrm{ppm})$} \\
\hline Testemunha & 98,35 & 123,20 & 221,55 & $1.407,35$ & $1.628,90$ \\
\hline B. decumbens - seca & 71,75 & 17,85 & 89,60 & $1.429,40$ & $1.519,00$ \\
\hline B. decumbens -águas & 74,90 & 14,70 & 89,60 & $1.570,10$ & $1.659,70$ \\
\hline Níveis de significância de F: & $\alpha^{*}$ & $\alpha$ & $\alpha$ & $\alpha$ & $\alpha$ \\
\hline Tratamentos & 5,90 & 0,03 & 0,01 & 79,17 & 81,72 \\
\hline Testemunha vs seca & 0,49 & 0,01 & 0,01 & 95,23 & 76,79 \\
\hline Testemunha vs águas & 0,95 & 0,01 & 0,01 & 66,11 & 93,39 \\
\hline Seca vs águas & 66,12 & 80,32 & 100,00 & 70,43 & 70,61 \\
\hline $\mathrm{CV}(\%)$ & 13,40 & 37,23 & 15,34 & 38,49 & 35,52 \\
\hline
\end{tabular}

* Porcentagem.

Tabela 5 - Níveis de significância e valores médios dos teores de nitrogênio total e de suas formas no solo onde se cultivou o trigo, após incorporação de $B$. decumbens

\begin{tabular}{|c|c|c|c|c|c|}
\hline \multirow{2}{*}{ Tratamento } & $\mathrm{N}-\mathrm{NH}_{3}$ & $\mathrm{~N}-\mathrm{NO}_{3}$ & N-Mineral & N-Orgânico & N-Total \\
\hline & \multicolumn{5}{|c|}{ (ppm) } \\
\hline Testemunha & 95,90 & 29,05 & 124,95 & $1.035,65$ & $1.160,60$ \\
\hline B. decumbens - seca & 91,00 & 29,05 & 120,05 & 971,25 & $1.091,30$ \\
\hline B. decumbens -águas & 89,95 & 26,25 & 116,20 & $1.481,20$ & $1.597,40$ \\
\hline Níveis de significância de F: & $\alpha^{*}$ & $\alpha$ & $\alpha$ & $\alpha$ & $\alpha$ \\
\hline Tratamentos & 6,48 & 67,64 & 8,61 & 1,46 & 1,24 \\
\hline Testemunha vs seca & 64,18 & 100,00 & 71,26 & 77,23 & 74,75 \\
\hline Testemunha vs águas & 57,34 & 58,88 & 51,47 & 7,21 & 6,89 \\
\hline Seca vs águas & 92,01 & 58,88 & 77,19 & 4,52 & 4,10 \\
\hline $\mathrm{CV}(\%)$ & 17,37 & 27,96 & 16,86 & 29,25 & 25,62 \\
\hline
\end{tabular}

* Porcentagem.

Tabela 6 - Níveis de significância e valores médios dos teores de nitrogênio total e de suas formas no solo onde se cultivou a soja, após incorporação de $B$. decumbens

\begin{tabular}{|c|c|c|c|c|c|}
\hline \multirow{2}{*}{ Tratamento } & $\mathrm{N}-\mathrm{NH}_{3}$ & $\mathrm{~N}-\mathrm{NO}_{3}$ & N-Mineral & N-Orgânico & N-Total \\
\hline & \multicolumn{5}{|c|}{$(\mathrm{ppm})$} \\
\hline Testemunha & 55,30 & 79,10 & 134,40 & $1.372,00$ & $1.506,40$ \\
\hline B. decumbens - seca & 47,60 & 11,90 & 59,50 & $1.664,60$ & $1.724,10$ \\
\hline B. decumbens -águas & 47,95 & 10,15 & 58,10 & $1.738,10$ & $1.796,20$ \\
\hline Níveis de significância de F: & $\alpha^{*}$ & $\alpha$ & $\alpha$ & $\alpha$ & $\alpha$ \\
\hline Tratamentos & 66,38 & 0,01 & 0,01 & 0,01 & 0,01 \\
\hline Testemunha vs seca & '25,14 & 0,01 & 0,01 & 0,28 & 0,82 \\
\hline Testemunha vs águas & ' 71,33 & 0,01 & 0,01 & 0,06 & 0,14 \\
\hline Seca vs águas & '32,07 & 61,20 & 74,90 & 9,01 & 8,04 \\
\hline $\mathrm{CV}(\%)$ & 12,51 & 3,61 & 3,83 & 3,78 & 3,39 \\
\hline
\end{tabular}

* Porcentagem. 
Tabela 7 - Níveis de significância e valores médios dos teores de nitrogênio total e de suas formas no solo onde se cultivou o feijão, após incorporação de $B$. decumbens

\begin{tabular}{|c|c|c|c|c|c|}
\hline \multirow{2}{*}{ Tratamento } & $\mathrm{N}-\mathrm{NH}_{3}$ & $\mathrm{~N}-\mathrm{NO}_{3}$ & N-Mineral & N-Orgânico & N-Total \\
\hline & \multicolumn{5}{|c|}{$(\mathrm{ppm})$} \\
\hline Testemunha & 49,70 & 50,75 & 100,45 & 877,45 & 977,90 \\
\hline B. decumbens - seca & 68,60 & 14,70 & 83,30 & $1.882,30$ & $1.965,60$ \\
\hline B. decumbens - águas & 69,30 & 11,20 & 80,50 & $1.845,90$ & $1.926,40$ \\
\hline Níveis de significância de F: & $\alpha^{*}$ & $\alpha$ & $\alpha$ & $\alpha$ & $\alpha$ \\
\hline Tratamentos & 16,16 & 2,82 & 61,50 & 4,15 & 4,38 \\
\hline Testemunha vs seca & 3,92 & 0,41 & 30,38 & 0,45 & 0,48 \\
\hline Testemunha vs águas & 3,40 & 0,24 & 23,98 & 0,55 & 0,60 \\
\hline Seca vs águas & 92,96 & 70,94 & 86,30 & 89,11 & 88,20 \\
\hline $\mathrm{CV}(\%)$ & 19,41 & 56,07 & 28,20 & 26,53 & 24,92 \\
\hline
\end{tabular}

* Porcentagem.

Tabela 8 - Níveis de significância e valores médios dos teores de nitrogênio total e de suas formas no solo onde se cultivou o algodão, após incorporação de B. decumbens

\begin{tabular}{|c|c|c|c|c|c|}
\hline \multirow{2}{*}{ Tratamento } & $\mathrm{N}-\mathrm{NH}_{3}$ & $\mathrm{~N}-\mathrm{NO}_{3}$ & N-Mineral & N-Orgânico & N-Total \\
\hline & \multicolumn{5}{|c|}{ (ppm) } \\
\hline Testemunha & 78,75 & 80,15 & 158,90 & 954,00 & $1.103,90$ \\
\hline B. decumbens - seca & 74,55 & 37,10 & 111,65 & $2.169,65$ & $2.281,30$ \\
\hline B. decumbens - águas & 92,75 & 22,05 & 114,80 & $1.698,90$ & $1.813,70$ \\
\hline Níveis de significância de F: & $\alpha *$ & $\alpha$ & $\alpha$ & $\alpha$ & $\alpha$ \\
\hline Tratamentos & 32,06 & 0,30 & 20,48 & 3,93 & 3,99 \\
\hline Testemunha vs seca & 74,81 & 0,10 & 4,51 & 0,20 & 0,21 \\
\hline Testemunha vs águas & 30,00 & 0,01 & 5,77 & 2,39 & 2,72 \\
\hline Seca vs águas & 18,76 & 11,45 & 87,82 & 12,06 & 11,35 \\
\hline $\mathrm{CV}(\%)$ & 24,35 & 28,94 & 24,51 & 26,71 & 24,01 \\
\hline
\end{tabular}

* Porcentagem.

Tabela 9 - Níveis de significância e valores médios dos teores de nitrogênio total e de suas formas no solo onde se cultivou $B$. decumbens, após a incorporação de B. decumbens

\begin{tabular}{|c|c|c|c|c|c|}
\hline \multirow{2}{*}{ Tratamento } & $\mathrm{N}-\mathrm{NH}_{3}$ & $\mathrm{~N}-\mathrm{NO}_{3}$ & N-Mineral & N-Orgânico & N-Total \\
\hline & \multicolumn{5}{|c|}{ (ppm) } \\
\hline Testemunha & 102,90 & 119,00 & 221,90 & 692,30 & 914,20 \\
\hline B. decumbens - seca & 61,60 & 25,55 & 87,15 & $1.753,85$ & $1.841,00$ \\
\hline B. decumbens - águas & 61,95 & 19,25 & 81,20 & $1.416,10$ & $1.497,30$ \\
\hline Níveis de significância de F: & $\alpha^{*}$ & $\alpha$ & $\alpha$ & $\alpha$ & $\alpha$ \\
\hline Tratamentos & 2,70 & 0,19 & 0,37 & 9,41 & 13,88 \\
\hline Testemunha vs seca & 0,53 & 0,02 & 0,04 & 0,80 & 4,45 \\
\hline Testemunha vs águas & 0,55 & 0,01 & 0,03 & 4,39 & 8,65 \\
\hline Seca vs águas & 97,51 & 67,10 & 80,31 & 29,72 & 28,27 \\
\hline $\mathrm{CV}(\%)$ & 22,79 & 41,38 & 28,05 & 37,20 & 33,29 \\
\hline
\end{tabular}

* Porcentagem. 
Quanto aos teores de nitrato, exceção feita ao experimento utilizando trigo como planta indicadora, eles foram sempre inferiores nos tratamentos com incorporação de B. decumbens. Nas outras seis culturas, os contrastes entre a testemunha e os demais tratamentos foram sempre significativos em baixos niveis de probabilidade.

De modo geral, ficou evidente que a incorporação de matéria seca de $B$. decumbens reduziu drasticamente os teores de nitrato no solo ao término dos experimentos. Essas reduções não resultaram da absorção diferenciada pelas culturas, nos diferentes tratamentos.

A incorporação de $B$. decumbens aumentou significativamente os teores de amônia no solo, no experimento com a cultura do feijão. Comportamento inverso foi verificado nos experimentos com a cultura do arroz e a própria Brachiaria. Nas demais culturas, os valores médios, para os três tratamentos, foram próximos.

A cultura do arroz possui a capacidade de absorver $\mathrm{N}$ tanto na forma nítrica quanto na amoniacal. Contudo, a hipótese de que os menores teores de amônia no solo resultam de maior absorção de amônia pelas plantas de arroz, como resultado de menor disponibilidade de nitrato, não encontra suporte nos resultados. Observa-se, na Tabela 17, que a extração total da cultura corresponde a apenas 6,62 e $2,17 \%$ do $\mathrm{N}$ amoniacal disponível no substrato, nos tratamentos com incorporação de matéria seca de $B$. decumbens das secas e águas, respectivamente. Embora não se conheça a forma preferencial de absorção de $\mathrm{N}$ por $\mathrm{B}$. decumbens, a extração de $\mathrm{N}$ pela cultura também é pouco expressiva quando comparada às diferenças nos teores de amônia no solo. Não foi possivel encontrar justificativas para o menor teor de amônia $\left(\mathrm{NH}_{3}\right)$ no solo da testemunha, no experimento com a cultura do feijão.

Quanto ao fracionamento do $\mathrm{N}$ no solo, a observação mais importante refere-se à intensa redução dos teores de nitrato $\left(\mathrm{NO}_{3}\right)$ no solo, nos tratamentos com incorporação de matéria seca de B. decumbens. Existem duas hipóteses para justificar os resultados. No primeiro caso, há a possibilidade de que os menores teores de nitrato resultem da inibição do processo de nitrificação pela matéria seca de $B$. decumbens. Reduções na intensidade de nitrificação, como resultado da liberação de compostos tóxicos no solo, foram verificadas por vários pesquisadores (Meilejohn, 1962, 1968; Boughey et al., 1964; Neal Jr., 1969).

A segunda hipótese justificaria os menores teores de nitrato como resultado de um maior consumo dessa fração de N-mineral. O maior consumo poderia resultar da incorporação do $\mathrm{N}$-nítrico à matéria orgânica do solo durante o processo de decomposição da matéria seca adicionada.

A possibilidade de estímulo à desnitrificação pode ser praticamente descartada em função de não terem ocorrido, em nenhum dos sete experimentos, reduções dos teores totais de $\mathrm{N}$ nos tratamentos com adição de matéria seca de B. decumbens; ao contrário, houve aumentos que sobrelevaram as quantidades de $\mathrm{N}$ presentes na matéria seca incorporada.

Adotando, como exemplo, o milho e trabalhando com os valores médios para B. decumbens coletada nas estações seca e chuvosa, a adição de matéria seca praticamente não alterou o teor de amônia, reduziu o teor de nitrato em 50 ppm (257 mg por vaso) e aumentou os teores de N-orgânico e total em 314 e 263 ppm, correspondendo a 1.617 e $1.354 \mathrm{mg}$ por vaso, respectivamente. A quantidade média de $\mathrm{N}$ presente na matéria seca adicionada foi de $1.384 \mathrm{mg}$ por vaso ou o suficiente para elevar o teor de $\mathrm{N}$ no substrato final em 269 ppm. Como se verá adiante, a absorção de N pela cultura do milho na testemunha excedeu em $228 \mathrm{mg}$ por vaso a absorção média nos demais tratamentos. A análise dos dados indica que a elevação do conteúdo total de $\mathrm{N}$ no solo foi bastante próxima da quantidade total de $\mathrm{N}$ acrescida ao substrato pela adição da matéria seca de B. decumbens (1.354 e $1.384 \mathrm{mg}$ por vaso, respectivamente).

$\mathrm{O}$ aumento na quantidade de N-orgânico (1.617 $\mathrm{mg}$ por vaso) excedeu o aumento da quantidade total de N (1.354 mg por vaso) em $263 \mathrm{mg}$ por vaso; esse valor é compatível com os $257 \mathrm{mg}$ por vaso correspondentes ao decréscimo no teor de nitrato. Embora falte acrescentar ao balanço o $\mathrm{N}$ extraído e adicionado na forma de fertilizante, os resultados sugerem que a redução do teor de nitrato resultou da incorporação deste à matéria orgânica do solo. 
Os resultados referentes aos teores de $\mathrm{N}$ inorgânico e suas frações (nítrica e amoniacal) mostraram-se de grande relevância para o entendimento dos efeitos de B. decumbens sobre o crescimento de plantas cultivadas.

Nas Tabelas 10 a 16 são apresentados os resultados referentes às análises biométricas das culturas, quando do encerramento dos experimentos. De todas as características analisadas, o teor de clorofila foi a menos sensivel aos tratamentos utilizados. Contudo, mesmo esta característica foi reduzida significamente pela adição de matéria seca de B. decumbens, na maioria das culturas estudadas. Todas as demais características foram drasticamente reduzidas, em todas as culturas, pela adição de matéria seca de $B$. decumbens coletada na época das secas ou das águas.

Considerando que foram analisadas sete características para um total de sete espécies, são estabelecidas 49 combinações das variáveis. Em 48 dessas combinações, as médias do tratamento com adição de matéria seca de $B$. decumbens das secas sobrelevaram as médias do tratamento com adição de B. decumbens coletada na estação chuvosa; em 26 dessas 48 combinações o contraste envolvendo os dois tratamentos foi significativo em baixos niveis de probabilidade. Utilizando cálculos simples de probabilidade, a chance de que essa combinação de resultados entre os tratamentos tenha ocorrido por efeito exclusivo do acaso é de uma em aproximadamente 281 trilhões de oportunidades. Não há dúvida, portanto, de que, independentemente da natureza dos efeitos inibitórios observados, estes foram mais intensos quando se utilizou matéria seca de $B$. decumbens coletada na estação chuvosa. Retornando aos resultados referentes aos teores de nitrato, amônia e nitrogênio inorgânico no solo, ficou evidente a proximidade dos resultados obtidos para os dois tipos de matéria seca de Brachiaria.

Os resultados sugerem que, mesmo que os efeitos inibitórios encontrados sejam primariamente devido a alterações na disponibilidade de nitrato, há um segundo fator contribuindo para a maior redução de crescimento resultante da adição de matéria seca de $B$. decumbens coletada na estação chuvosa.

Na Tabela 17 estão apresentados os teores ( $\mathrm{g} \mathrm{kg}^{-1}$ ) e as quantidades de nitrogênio acumulado pela parte aérea das culturas (mg por vaso). Deve ser destacado que os teores de $\mathrm{N}$ foram reduzidos em todas as culturas estudadas. Mesmo na cultura do trigo, em que os efeitos foram menos intensos, o contraste entre a testemunha e o tratamento com matéria seca de B. decumbens, coletada na estação chuvosa, foi significativo em nível de 19,33\%, indicando uma provável diferença entre os tratamentos. $A$ adição de matéria seca de $B$. decumbens coletada na estação chuvosa intensificou os efeitos sobre as quantidades totais extraídas, reduzindo os teores de nitrogênio em todas as culturas estudadas.

Tabela 10 - Valores médios do teor de clorofila, quantidade de clorofila, área foliar, massa seca de folhas, de caules, de raízes e massa seca total de milho, com os níveis de significância de F

\begin{tabular}{|c|c|c|c|c|c|c|c|}
\hline Tratamento & $\begin{array}{l}\text { Teor de } \\
\text { clorofila }\end{array}$ & $\begin{array}{c}\text { Quantidade de } \\
\text { clorofila }\end{array}$ & Área foliar & $\begin{array}{c}\text { Massa seca } \\
\text { de folhas }\end{array}$ & $\begin{array}{c}\text { Massa seca } \\
\text { de caules }\end{array}$ & $\begin{array}{c}\text { Massa seca } \\
\text { de raízes }\end{array}$ & $\begin{array}{c}\text { Massa seca } \\
\text { total }\end{array}$ \\
\hline & $\left(\mathrm{mg} \mathrm{dm}^{-2}\right)$ & (mg por vaso) & $\left(\mathrm{dm}^{2}\right)$ & \multicolumn{4}{|c|}{$(\mathrm{g})$} \\
\hline Testemunha & 3,83 & 60,73 & 15,80 & $\overline{3,69}$ & 2,63 & 4,32 & 10,63 \\
\hline B. decumbens - seca & 3,33 & 18,37 & 5,39 & 0,99 & 0,71 & 1,93 & 3,63 \\
\hline B. decumbens - águas & 2,76 & 9,29 & 3,19 & 0,61 & 0,43 & 1,41 & 2,44 \\
\hline Níveis de significância de F: & $\alpha^{*}$ & $\alpha$ & $\alpha$ & $\alpha$ & $\alpha$ & $\alpha$ & $\alpha$ \\
\hline Tratamentos & 0,40 & 0,01 & 0,01 & 0,01 & 0,01 & 1,25 & 0,06 \\
\hline Testemunha vs seca & 1,82 & 0,01 & 0,01 & 0,01 & 0,01 & 0,22 & 0,01 \\
\hline Testemunha vs águas & 0,02 & 0,01 & 0,01 & 0,01 & 0,01 & 0,07 & 0,01 \\
\hline Seca vs águas & 1,04 & 7,96 & 6,29 & 23,71 & 18,20 & 36,53 & 25,24 \\
\hline $\mathrm{CV}(\%)$ & 8,18 & 23,71 & 19,79 & 26,81 & 24,49 & 33,59 & 27,30 \\
\hline
\end{tabular}

\footnotetext{
* Porcentagem.
} 
Tabela 11 - Valores médios do teor de clorofila, quantidade de clorofila, área foliar, massa seca de folhas, de caules, de raízes e massa seca total de arroz, com os níveis de significância de F

\begin{tabular}{|c|c|c|c|c|c|c|c|}
\hline \multirow[t]{2}{*}{ Tratamento } & $\begin{array}{l}\text { Teor de } \\
\text { clorofila }\end{array}$ & $\begin{array}{c}\text { Quantidade de } \\
\text { clorofila }\end{array}$ & Área foliar & $\begin{array}{c}\text { Massa seca } \\
\text { de folhas }\end{array}$ & $\begin{array}{c}\text { Massa seca } \\
\text { de caules }\end{array}$ & $\begin{array}{l}\text { Massa seca } \\
\text { de raízes }\end{array}$ & $\begin{array}{c}\text { Massa seca } \\
\text { total }\end{array}$ \\
\hline & $\left(\mathrm{mg} \mathrm{dm}^{-2}\right)$ & (mg por vaso) & $\left(\mathrm{dm}^{2}\right)$ & \multicolumn{4}{|c|}{ (g) } \\
\hline Testemunha & 3,00 & 6,52 & 2,16 & 0,73 & 0,46 & 0,82 & 2,01 \\
\hline B. decumbens - seca & 2,75 & 3,30 & 1,16 & 0,40 & 0,29 & 0,67 & 1,36 \\
\hline B. decumbens - águas & 2,43 & 0,66 & 0,26 & 0,19 & 0,13 & 0,47 & 0,79 \\
\hline Níveis de significância de F: & $\alpha^{*}$ & $\alpha$ & $\alpha$ & $\alpha$ & $\alpha$ & $\alpha$ & $\alpha$ \\
\hline Tratamentos & 23,72 & 0,37 & 0,22 & 0,06 & 0,95 & 6,34 & 0,73 \\
\hline Testemunha vs seca & 20,52 & 0,42 & 0,36 & 0,04 & 1,11 & 13,72 & 0,89 \\
\hline Testemunha vs águas & 1,43 & "3, 0,01 & 0,01 & 0,01 & 0,03 & 0,44 & 0,02 \\
\hline Seca vs águas & 12,06 & 1,20 & 0,61 & 0,75 & 1,93 & 5,24 & 1,80 \\
\hline $\mathrm{CV}(\%)$ & 10,66 & 36,94 & 32,35 & 20,76 & 29,25 & 21,62 & 21,77 \\
\hline
\end{tabular}

* Porcentagem.

Tabela 12 - Valores médios do teor de clorofila, quantidade de clorofila, área foliar, massa seca de folhas, de caules, de raízes e massa seca total de trigo, com os níveis de significância de $\mathrm{F}$

\begin{tabular}{|c|c|c|c|c|c|c|c|}
\hline Tratamento & $\begin{array}{l}\text { Teor de } \\
\text { clorofila }\end{array}$ & $\begin{array}{l}\text { Quantidade de } \\
\text { clorofila }\end{array}$ & Área foliar & $\begin{array}{c}\text { Massa seca } \\
\text { de folhas }\end{array}$ & $\begin{array}{c}\text { Massa seca } \\
\text { de caules }\end{array}$ & $\begin{array}{c}\text { Massa seca } \\
\text { de raízes }\end{array}$ & $\begin{array}{c}\text { Massa seca } \\
\text { total }\end{array}$ \\
\hline & $\left(\mathrm{mg} \mathrm{dm}^{-2}\right)$ & (mg por vaso) & $\left(\mathrm{dm}^{2}\right)$ & \multicolumn{4}{|c|}{ (g) } \\
\hline Testemunha & 3,41 & 25,44 & 7,42 & 1,68 & 0,87 & 1,41 & 3,96 \\
\hline B. decumbens - seca & 3,73 & 11,27 & 3,01 & 0,40 & 0,26 & 0,65 & 1,31 \\
\hline B. decumbens - águas & 3,63 & 5,94 & 1,63 & 0,27 & 0,17 & 0,69 & 1,12 \\
\hline Níveis de significância de F: & $\alpha *$ & $\alpha$ & $\alpha$ & $\alpha$ & $\alpha$ & $\alpha$ & $\alpha$ \\
\hline Tratamentos & n & 0,05 & 0,02 & 0,01 & 0,01 & 1,52 & 0,01 \\
\hline Testemunha vs seca & 3,54 & 0,02 & 0,01 & 0,01 & 0,01 & 0,18 & 0,01 \\
\hline Testemunha vs águas & 11,59 & 0,01 & 0,01 & 0,01 & 0,01 & 0,23 & 0,01 \\
\hline Seca vs águas & 46,66 & 4,12 & 3,95 & 33,22 & 21,08 & 85,18 & 49,70 \\
\hline $\mathrm{CV}(\%)$ & 5,65 & 24,38 & 22,09 & 25,34 & 24,72 & 28,81 & 19,84 \\
\hline
\end{tabular}

* Porcentagem.

Tabela 13 - Valores médios do teor de clorofila, quantidade de clorofila, área foliar, massa seca de folhas, de caules, de raízes e massa seca total de soja, com os níveis de significância de F

\begin{tabular}{|c|c|c|c|c|c|c|c|}
\hline Tratamento & $\begin{array}{l}\text { Teor de } \\
\text { clorofila }\end{array}$ & $\begin{array}{l}\text { Quantidade de } \\
\text { clorofila }\end{array}$ & Área foliar & $\begin{array}{c}\text { Massa seca } \\
\text { de folhas }\end{array}$ & $\begin{array}{c}\text { Massa seca } \\
\text { de caules }\end{array}$ & $\begin{array}{c}\text { Massa seca } \\
\text { de raízes }\end{array}$ & $\begin{array}{c}\text { Massa seca } \\
\text { total }\end{array}$ \\
\hline & $\left(\mathrm{mg} \mathrm{dm}^{-2}\right)$ & (mg por vaso) & $\left(\mathrm{dm}^{2}\right)$ & \multicolumn{4}{|c|}{$(\mathrm{g})$} \\
\hline Testemunha & 3,91 & 48,93 & 12,54 & 3,05 & 2,22 & 1,54 & 6,81 \\
\hline B. decumbens - seca & 2,76 & 18,37 & 6,59 & 1,26 & 1,04 & 1,37 & 3,66 \\
\hline B. decumbens - águas & 2,58 & 13,09 & 4,96 & 1,09 & 0,88 & 1,22 & 3,19 \\
\hline Níveis de significância de F: & $\alpha^{*}$ & $\alpha$ & $\alpha$ & $\alpha$ & $\alpha$ & $\alpha$ & $\alpha$ \\
\hline Tratamentos & 0,19 & 0,01 & 0,05 & 0,02 & 0,03 & 21,93 & 0,17 \\
\hline Testemunha vs seca & 0,02 & 0,01 & 0,01 & 0,01 & 0,01 & 40,79 & 0,02 \\
\hline Testemunha vs águas & 0,01 & 0,01 & 0,01 & 0,01 & 0,01 & 13,88 & 0,01 \\
\hline Seca vs águas & 34,03 & 11,92 & 8,15 & 43,93 & 28,11 & 46,31 & 46,31 \\
\hline $\mathrm{CV}(\%)$ & 9,41 & 17,85 & 16,14 & 17,48 & 16,07 & 22,35 & 17,29 \\
\hline
\end{tabular}

* Porcentagem. 
Tabelas 14 - Valores médios do teor de clorofila, quantidade de clorofila, área foliar, massa seca de folhas, de caules, de raízes e massa seca total de feijão, com os níveis de significância de F

\begin{tabular}{|c|c|c|c|c|c|c|c|}
\hline Tratamento & $\begin{array}{l}\text { Teor de } \\
\text { clorofila }\end{array}$ & \begin{tabular}{|c|} 
Quantidade de \\
clorofila
\end{tabular} & Área foliar & $\begin{array}{c}\text { Massa seca } \\
\text { de folhas }\end{array}$ & $\begin{array}{c}\text { Massa seca } \\
\text { de caules }\end{array}$ & $\begin{array}{l}\text { Massa seca } \\
\text { de raízes }\end{array}$ & $\begin{array}{c}\text { Massa seca } \\
\text { total }\end{array}$ \\
\hline & $\left(\mathrm{mg} \mathrm{dm}^{-2}\right)$ & (mg por vaso) & $\left(\mathrm{dm}^{2}\right)$ & \multicolumn{4}{|c|}{$(\mathrm{g})$} \\
\hline Testemunha & 3,68 & 42,40 & 11,54 & 2,64 & 1,05 & 1,79 & 5,47 \\
\hline B. decumbens - seca & 2,47 & 8,89 & 3,36 & 0,79 & 0,21 & 0,63 & 1,63 \\
\hline B. decumbens - águas & 2,23 & "2, 2,58 & 1,17 & 0,37 & 0,14 & 0,42 & 0,92 \\
\hline Níveis de significância de F: & $\alpha^{*}$ & $\alpha$ & $\alpha$ & $\alpha$ & $\alpha$ & $\alpha$ & $\alpha$ \\
\hline Tratamentos & 0,23 & 0,01 & 0,01 & 0,02 & 0,01 & 0,01 & 0,01 \\
\hline Testemunha vs seca & 0,03 & 0,01 & 0,01 & 0,01 & 0,01 & 0,01 & 0,01 \\
\hline Testemunha vs águas & 0,01 & 0,01 & 0,01 & 0,01 & 0,01 & 0,01 & 0,01 \\
\hline Seca vs águas & 26,83 & 3,37 & 1,32 & 8,64 & 11,91 & 12,34 & 8,46 \\
\hline $\mathrm{CV}(\%)$ & 11,53 & 21,71 & 20,40 & 27,20 & 15,16 & 20,64 & 21,49 \\
\hline
\end{tabular}

* Porcentagem.

Tabela 15 - Valores médios do teor de clorofila, quantidade de clorofila, área foliar, massa seca de folhas, de caules, de raízes e massa seca total de algodão, com os níveis de significância de F

\begin{tabular}{|l|c|c|c|c|c|c|c|}
\hline \multirow{2}{*}{ Tratamento } & $\begin{array}{c}\text { Teor de } \\
\text { clorofila }\end{array}$ & $\begin{array}{c}\text { Quantidade de } \\
\text { clorofila }\end{array}$ & Área foliar & $\begin{array}{c}\text { Massa seca } \\
\text { de folhas }\end{array}$ & $\begin{array}{c}\text { Massa seca } \\
\text { de caules }\end{array}$ & $\begin{array}{c}\text { Massa seca } \\
\text { de raízes }\end{array}$ & $\begin{array}{c}\text { Massa seca } \\
\text { total }\end{array}$ \\
\cline { 2 - 8 } & $\left(\mathrm{mg} \mathrm{dm}^{-2}\right)$ & $(\mathrm{mg}$ por vaso $)$ & $\left(\mathrm{dm}^{2}\right)$ & \multicolumn{4}{|c|}{$(\mathrm{g})$} \\
\hline Testemunha & 4,25 & 12,12 & $2, .85$ & 1,25 & 0,67 & 1,26 & 3,18 \\
\hline B. decumbens - seca & 3,84 & 5,44 & 1,42 & 0,62 & 0,27 & 0,40 & 1,28 \\
\hline B. decumbens - águas & 3,67 & 2,80 & 0,76 & 0,35 & 0,19 & 0,27 & 0,80 \\
\hline Níveis de significância de F: & $\alpha^{*}$ & $\alpha$ & $\alpha$ & $\alpha$ & $\alpha$ & $\alpha$ & $\alpha$ \\
\hline Tratamenton & 23,08 & 0,02 & 0,01 & 0,07 & 0,05 & 11,18 & 1,08 \\
\hline Testemunha vs seca & 6,23 & 0,01 & 0,01 & 0,02 & 0,01 & 2,62 & 0,23 \\
\hline Testemunha vs águas & 1,48 & 0,01 & 0,01 & 0,01 & 0,01 & 1,34 & 0,06 \\
\hline Seca vs águas & 38,05 & 1,75 & 0,50 & 2,97 & $20,53$. & 67,10 & 29,65 \\
\hline CV (\%) & 7,56 & 20,66 & 16,32 & 21,64 & 22,65 & 78,53 & 38,86 \\
\hline
\end{tabular}

* Porcentagem.

Tabela 16 - Valores médios do teor de clorofila, quantidade de clorofila, área foliar, massa seca de folhas, de caules, de raízes e massa seca total de B. decumbens, com os níveis de significância de F

\begin{tabular}{|l|c|c|c|c|c|c|c|}
\hline \multirow{2}{*}{ Tratamento } & $\begin{array}{c}\text { Teor de } \\
\text { clorofila }\end{array}$ & $\begin{array}{c}\text { Quantidade de } \\
\text { clorofila }\end{array}$ & Área foliar & $\begin{array}{c}\text { Massa seca } \\
\text { de folhas }\end{array}$ & $\begin{array}{c}\text { Massa seca } \\
\text { de caules }\end{array}$ & $\begin{array}{c}\text { Massa seca } \\
\text { de raízes }\end{array}$ & $\begin{array}{c}\text { Massa seca } \\
\text { total }\end{array}$ \\
\cline { 2 - 8 } & $\left(\mathrm{mg} \mathrm{dm}^{-2}\right)$ & $(\mathrm{mg}$ por vaso $)$ & $\left(\mathrm{dm}^{2}\right)$ & \multicolumn{4}{|c|}{$(\mathrm{g})$} \\
\hline Testemunha & 3,35 & 2,44 & 0,73 & 0,17 & 0,06 & 0,05 & 0,22 \\
\hline $\begin{array}{l}\text { B. decumbens } \text { - seca } \\
\text { B. decumbens } \text { - águas }\end{array}$ & 3,00 & 0,71 & 0,23 & 0,04 & 0,02 & 0,03 & 0,09 \\
\hline Níveis de significância de F: & 1,99 & 0,22 & 0,11 & 0,02 & 0,01 & 0,03 & 0,06 \\
\hline Tratamentos & $\alpha^{*}$ & $\alpha$ & $\alpha$ & $\alpha$ & $\alpha$ & $\alpha$ & $\alpha$ \\
\hline Testemunha vs seca & 0,12 & 0,01 & 0,01 & 0,04 & 0,05 & 2,15 & 0,11 \\
\hline Testemunha vs águas & 7,21 & 0,01 & 0,01 & 0,01 & 0,01 & 0,15 & 0,02 \\
\hline Seca vs águas & 0,01 & 0,01 & 0,01 & 0,01 & 0,01 & 0,31 & 0,01 \\
\hline CV (\%) & 0,03 & 2,89 & 5,37 & 89,7 & 49,96 & 61,57 & 19,36 \\
\hline
\end{tabular}

* Porcentagem. 
Tabela 17 - Níveis de significância e valores médios dos teores foliares de nitrogênio de milho, arroz, trigo, soja, feijão, algodão e capim-braquiária

\begin{tabular}{|c|c|c|c|c|c|c|c|c|c|c|c|c|c|c|}
\hline \multirow{3}{*}{ Tratamento } & \multicolumn{2}{|c|}{ Milho } & \multicolumn{2}{|c|}{ Arroz } & \multicolumn{2}{|c|}{ Trigo } & \multicolumn{2}{|c|}{ Soja } & \multicolumn{2}{|c|}{ Feijão } & \multicolumn{2}{|c|}{ Algodão } & \multicolumn{2}{|c|}{ B. decumbens } \\
\hline & \multicolumn{14}{|c|}{ Teores Foliares de Nitrogênio } \\
\hline & $\left(\mathrm{g} \mathrm{kg}^{-1}\right)$ & $\begin{array}{c}\text { (mg } \\
\text { por } \\
\text { vaso) }\end{array}$ & $\left(\mathrm{g} \mathrm{kg}^{-1}\right)$ & $\begin{array}{c}\text { (mg } \\
\text { por } \\
\text { vaso) }\end{array}$ & $\left(\mathrm{g} \mathrm{kg}^{-1}\right)$ & $\begin{array}{c}\text { (mg } \\
\text { por } \\
\text { vaso) }\end{array}$ & $\left(\mathrm{g} \mathrm{kg}^{-1}\right)$ & $\begin{array}{c}\text { (mg } \\
\text { por } \\
\text { vaso) }\end{array}$ & $\left(\mathrm{g} \mathrm{kg}^{-1}\right)$ & $\begin{array}{c}\text { (mg } \\
\text { por } \\
\text { vaso) }\end{array}$ & $\left(\mathrm{g} \mathrm{kg}^{-1}\right)$ & $\begin{array}{c}\text { (mg } \\
\text { por } \\
\text { vaso) }\end{array}$ & $\left(\mathrm{g} \mathrm{kg}^{-1}\right)$ & $\begin{array}{c}\text { (mg } \\
\text { por } \\
\text { vaso) }\end{array}$ \\
\hline Testemunha & 44,30 & 276,81 & 56,04 & 66,73 & 51,85 & 132,88 & 53,50 & 282,55 & 60,28 & 222,80 & 46,52 & 88,24 & 45,21 & 7,87 \\
\hline B. decumbens - seca & 40,53 & 68,53 & 47,14 & 34,10 & 45,46 & 30,01 & 32,85 & 76,95 & 36,57 & 39,43 & 31,14 & 27,74 & 40,59 & 2,28 \\
\hline B. decumbens - águas & 26,74 & 29,74 & 35,53 & 11,20 & 46,55 & 20,39 & 23,74 & 48,29 & 18,56 & 9,48 & 19,78 & 11,54 & 36,19 & 1,31 \\
\hline $\begin{array}{l}\text { Níveis de } \\
\text { significância de F: }\end{array}$ & $\alpha^{*}$ & $\alpha$ & $\alpha$ & $\alpha$ & $\alpha$ & $\alpha$ & $\alpha$ & $\alpha$ & $\alpha$ & $\alpha$ & $\alpha$ & $\alpha$ & $\alpha$ & $\alpha$ \\
\hline Tratamentos & 5,50 & 0,01 & 11,30 & 0,60 & 32,51 & 0,01 & 0,33 & 0,03 & 0,01 & 0,01 & 0,33 & 0,01 & 21,43 & 0,01 \\
\hline Testemunha vs seca & 40,88 & 0,01 & 18,50 & 0,47 & 12,50 & 0,01 & 0,12 & 0,01 & 0,01 & 0,01 & 0,35 & 0,01 & 17,59 & 0,01 \\
\hline Testemunha vs águas & 0,37 & 0,01 & 1,02 & 0,02 & 19,33 & 0,01 & 0,01 & 0,01 & 0,01 & 0,01 & 0,01 & 0,01 & 1,99 & 0,01 \\
\hline Seca vs águas & 1,29 & 7,92 & 9,50 & 2,62 & 77,69 & 35,63 & 6,26 & 27,11 & 0,05 & 8,44 & 1,68 & 1,00 & 19,51 & 14,02 \\
\hline $\mathrm{CV}(\%)$ & 18,41 & 24,40 & 20,97 & 35,61 & 12,30 & 25,46 & 18,15 & 28,20 & 12,99 & 26,55 & 18,36 & 17,96 & 12,10 & 24,73 \\
\hline
\end{tabular}

* Porcentagem.

Analisando conjuntamente os sete experimentos, verificou-se, primeiramente, que a matéria seca de $B$. decumbens coletada na estação chuvosa apresentou reduções mais intensas no crescimento das plantas-teste. Das sete culturas testadas, a própria $B$. decumbens apresentou maior sensibilidade aos efeitos de sua matéria seca.

A hipótese de que os menores teores de nitrato resultam da inibição do processo de nitrificação pela matéria seca de $B$. decumbens foi a que encontrou maior suporte nos dados obtidos. Os efeitos restritivos sobre o crescimento das plantas testadas tiveram como causa primária as alterações na disponibilidade de nitrato, mas, provavelmente, existe um segundo fator contribuindo para a redução de crescimento resultante da adição de $B$. decumbens no solo. Este segundo fator corresponderia a agentes tóxicos (aleloquímico) liberados durante a decomposição de B. decumbens. Trabalhos de pesquisa relatam a existência de aleloquímicos como o ácido p-cumárico produzido pelo capim Brachiaria humidicola (Souza Filho et al., 2005) e o ácido aconítico (Strobel, 2001).

Nas condições em que foi realizado o presente trabalho, são válidas as seguintes conclusões: o crescimento das plantas de milho, arroz, trigo, soja, feijão, algodão e braquiária foi reduzido pela incorporação, ao solo, de 3,0\% (p/p) de matéria seca de B. decumbens coletada na estação seca ou chuvosa; das sete culturas testadas, a própria B. decumbens apresentou maior sensibilidade aos efeitos de sua matéria seca; e a matéria seca da parte aérea de $B$. decumbens reduziu, significativamente, os teores de nitrato no solo, em todos os estudos realizados.

\section{AGRADECIMENTOS}

Aos técnicos Dorival Pires de Arruda e Rosimeire Ballestero, do Laboratório de Análises Solo-Planta do Dep. de Produção Vegetal da FCA-UNESP, pelo apoio na execução do trabalho, e à CAPES, pelo apoio financeiro.

\section{LITERATURA CITADA}

BELL, D. T.; KOEPPE, D. E. Noncompetitive effects of giant foxtail on the growth of corn. Agron. J., v. 64, p. 321-325, 1972.

BHOWMIK, P. C.; DOLL, J. D. Evalution of allelopathic effects of selected weeds species on corn and soybeans. Proc. North Cent. Weed Control. Conf., v. 34, p. 43-45, 1979.

BHOWMIK, P. C.; DOLL, J. D. Corn and soybean response to allelopathic effects of weed and crop residues. Agron. J., v. 74, p. 601-606, 1982. 
BOUGHEY, A. S. et al. Antibiotic reactions between African savanna species. Nature, v. 203, p. 1302-1303, 1964.

BUCHHOLTZ, K. P. The influence of allelopathy on mineral nutrition. In: _. Biochemical interactions among plants. Washington: National Academic Science, 1971. p. 86-89.

COCHRAN, V. L.; ELLIOTT, L. F.; PAPENDICK, R. I. The production of phytotoxins from surface crop residues. Soil Sci. Am. J., v. 41, p. 903-908, 1977.

GRESSEL, J. B.; HOLM, L. G. Chemical inhibibition of cropgermination by weed seed and the nature of the inhibition by Abutilon theophrasti. Weed Res., v. 4, p. 44-53, 1964.

GUENZI, W. D.; McCALLA, T. M.; NORSTAD, F. A. Presence and persistence of phytotoxic substances in wheat, oat, corn, and sorghum residues. Agron. J., v. 59, p. 163166, 1967.

KEENEY, D. R.; NELSON, D. W. Methods for determination of inorganic nitrogen in soil and soil extracts. In: Methods of soil ana1ysis chemical and microbiological properties. 2.ed. Madison: A.L.Page, 1982. p. 711-730.

MEIKLEJOHN, J. Microbiology of the nitrogen cycle in some Ghana soils. Emp. J. Exp. Agric., v. 30, p. 115-26, 1962.

MEIKLEJOHN, J. Numbers of nitrifying bacteria in some Rhodesian soils under natural grass and improved pasture. J. Appl. Ecol., v. 5, p. 291-300, 1968.

MILLS, W. R. Nitrate accumulation in Uganda soils. East Afr. Agric. J., v. 19, p. 53-54, 1953.

MULLER, C. H. The role of chemical inhibition (allelopathy) in vegetation composition. Bull. Torrey Bot. Club., v. 93, p. 332-351, 1966.

NEAL Jr., L. Inhibition of nitrifyng bacteria by grass and forb root extracts. Can. J. Bot., v. 15, p. 633-635, 1969.
RAIJ, B.van.; QUAGGIO, J. A. Método de análise de solo para fins de fertilidade. B. Tec. IAC, n. 81, p. 1-31, 1983.

RICE, E. L. Allelopathy. 2.ed. New York: Academic Press, 1984. $422 \mathrm{p}$.

SCALÉA, M. J. Experiências do manejo de plantas daninhas nas condições do Cerrado. In: CONGRESSO BRASILEIRO DA CIÊNCIA DAS PLANTAS DANINHAS, 21., 1997,

Viçosa, MG. Palestras e Mesas Rendondas... Viçosa, MG: Sociedade Brasileira da Ciência das Plantas Daninhas, 1997. p. 29-32.

SOUZA, L. S. et al. Efeito alelopático de plantas daninhas e concentrações de capim-braquiaria (Brachiaria decumbens) no desenvolvimento inicial de eucalipto (Eucalyptus grandis). Planta Daninha, v. 21, n. 3, p. 343-354, 2003.

SOUZA, L. S. et al. Possíveis efeitos alelopáticos de Brachiaria decumbens Stapf. sobre o desenvolvimento inicial de limão cravo (Citrus limonia Osbeck). Planta Daninha, v. 15, n. 2, p. 122-129, 1997.

SOUZA FILHO, A. P. S.; PEREIRA, A. A. G.; BAYMA, J. C. Aleloquímico produzido pela gramínea forrageira Brachiaria humidicola. Planta Daninha, v. 23, n. 1, p. 25-32, 2005.

STIVEN, G. Production of antibiotic substances by roots of a grass [Trachypogon plumosus (H.B.K.) Nees] and Pentanisia variabilis (E. Mey.) Hary. (Rubiaceae). Nature, v. 170, p. 712-713, 1952.

STROBEL, B. W. Influence of vegetation on low-molecularweight carboxylic acids in soil solution - a review. Geoderma, v. 99, p. 169-198, 2001.

TEDESCO, M. J.; VOLRWEISS, S. J.; BOHNEN, H. Análise de solo, plantas e outros materiais. Porto Alegre: Universidade Federal do Rio Grande do Sul, 1985. 28 p. (Boletim Técnico, 5)

TUKEY Jr., R. H. Implications of allelopathy in agricultural plant science. Bot. Rev., v. 35, p. 1-16, 1969. 